\title{
Planning Resilient Infrastructure Systems
}


Downloaded by [] on [26/04/23]. Copyright @ ICE Publishing, all rights reserved. 


\section{Planning Resilient Infrastructure Systems}

Alexander H Hay

PhD, CEng, PEng, FICE, RSES, CRM

Southern Harbour Ltd, Toronto, ON, Canada 
Published by ICE Publishing, One Great George Street, Westminster, London SW1P 3AA

Full details of ICE Publishing representatives and distributors can be found at: www.icebookshop.com/bookshop_contact.asp

Other titles by ICE Publishing:

Doing it Differently: Systems for rethinking infrastructure, Second edition

David Blockley and Patrick Godfrey. ISBN 978-0-7277-6082-1

Financing Infrastructure Projects: A practical guide, Second edition Tony Mema and Faisal F Al-Thani. ISBN 978-0-7277-6336-5

Rethinking Masterplanning: Creating Quality Places

Husam AIWaer and Barbara IIIsley. ISBN 978-0-7277-6071-5

www.icebookshop.com

A catalogue record for this book is available from the British Library

ISBN 978-0-7277-6562-8

(C) Thomas Telford Limited 2021

ICE Publishing is a division of Thomas Telford Ltd, a wholly owned subsidiary of the Institution of Civil Engineers (ICE).

All rights, including translation, reserved. Except as permitted by the Copyright, Designs and Patents Act 1988, no part of this publication may be reproduced, stored in a retrieval system or transmitted in any form or by any means, electronic, mechanical, photocopying or otherwise, without the prior written permission of the Publisher, ICE Publishing, One Great George Street, Westminster, London SW1P 3AA.

This book is published on the understanding that the author is solely responsible for the statements made and opinions expressed in it and that its publication does not necessarily imply that such statements and/or opinions are or reflect the views or opinions of the publisher. While every effort has been made to ensure that the statements made and the opinions expressed in this publication provide a safe and accurate guide, no liability or responsibility can be accepted in this respect by the author or publisher.

While every reasonable effort has been undertaken by the author and the publisher to acknowledge copyright on material reproduced, if there has been an oversight please contact the publisher and we will endeavour to correct this upon a reprint.

Cover photo: From the bird's eye view of Alesund port town on the west coast of Norway, at the entrance to the Geirangerfjord. Colorful summer sunset at the Nord port. Andrew Mayovsky/Shutterstock

Commissioning Editor: Michael Fenton

Production Editor: Madhubanti Bhattacharyya

Marketing Specialist: April Nagy

Typeset by Academic + Technical, Bristol

Index created by Pierke Bosschieter

Printed and bound in Great Britain by TJ Books, Padstow 
$01 \ldots \ldots \ldots \ldots \ldots \ldots \ldots \ldots$ Introduction

02

A theory of infrastructure: how does infrastructure work?

2.1. A system of systems 22

2.2. Purpose 24

2.3. Value 26

2.4. Equilibrium 31

2.5. The role of risk 34

2.6. Common reference 38

2.7. Chapter summary 45

Bibliography $\quad 47$

Further reading $\quad 48$

03

Sustainable infrastructure: who do we build infrastructure for?

3.1. Origins

3.2. Informing sustainability decisions 55

3.3. Sustainability, influencing change 60

3.4. Ownership and social justice 63

3.5. Intelligent resourcing 66

3.6. Acceptable risk 68

3.7. Chapter summary 69

Bibliography $\quad 71$

$\begin{array}{ll}\text { Further reading } & 73\end{array}$

$04 \ldots \ldots \ldots \ldots \ldots \ldots \ldots \ldots \ldots$ Resilient infrastructure: adapting to an uncertain future?

4.1. Operational resilience 76

4.2. A spatial concept 79

4.3. A functional concept 81

4.4. Safe-to-fail 83

4.5. Hazard travel time 85

4.6. Continuity of purpose 88

4.7. Community and resilience 94

4.8. Chain of consequence 97

4.9. Black swans 101

4.10. Chapter summary 102 
05

Protecting value: ensuring continued use

5.1. Security planning

5.2. Risk-based understanding

5.3. Protection principles

5.4. Through-life value

5.5. Risk mapping

5.6. Levels of protection

5.7. Chapter summary

Bibliography

Further reading

06

\section{Infrastructure planning in theory: putting it} all together

6.1. An overview of the planning process 130

6.2. What do we know and understand? 132

6.3. What do we seek to achieve? 135

6.4. How will the infrastructure enable this outcome?

6.5. Approach

6.6. Beneficial capability

6.7. Community engagement

6.8. Common reference

6.9. Measuring outcome

6.10. Community value

153

6.11. Informing the business case 154

6.12. Chapter summary 157

Bibliography

Further reading

07

Infrastructure planning in practice:

a perspective on application

7.1. Articulating need 164

7.2. A vision of the future 167

7.3. A shared understanding of the vision 169

7.4. Changing the vision 172

7.5. Noise and liminality 174

7.6. New communities 177

7.7. Post-trauma communities 179

7.8. Equity of access 181

7.9. Information and communications technology (ICT)

7.10. Chapter summary 186

Bibliography 188

Further reading 190 
8.1. What is known

8.2. What we know that is unknown

8.3. What is potentially unimaginable

8.4. Integrated strategic planning

8.5. Resilience

8.6. Technology

8.7. Ethics and law

8.8. Concluding remarks

Bibliography

Further reading

Index 
Downloaded by [] on [26/04/23]. Copyright @ ICE Publishing, all rights reserved. 
During the winter of 1992-1993, we hacked and blasted $76 \mathrm{~km}$ of two-lane road through the Dinaric Alps into the interior of Bosnia-Herzegovina. An expedient-military road, Route Triangle carried essential humanitarian relief during the Bosnian War. With each season that followed, the road was gradually enhanced, only to be abandoned following the 1995 Dayton Peace Accords. The experience and example of Route Triangle spurred in me a lifelong interest in infrastructure. I was particularly interested in how infrastructure use and value could change so completely. I also wanted to understand how a successful project could fail its intended beneficiaries.

Over three decades, I have had the distinct privilege of working in many countries, variously as client, consultant and contractor, with some of the most capable engineers, architects, financiers and planners. More recently, I had the opportunity to investigate how my observations and experiences compared with academic teachings and to conduct research. For me, infrastructure is, quite simply, fascinating. Water infrastructure has had a more profound and lasting effect on public health than any number of physicians. These infrastructure systems have allowed us to advance civilisation, densify cities and project trade. Improvements in communications and energy infrastructure systems have advanced economies around the world. Yet, it is often misunderstood and misapplied despite all that infrastructure is and enables us to do.

Hindsight is, as they say, 20/20. After navigating the complexities of planning and implementing a new infrastructure scheme, someone will identify the real and perceived failings in the delivered works. I have conducted audits of infrastructure schemes on behalf of underwriters, financiers and owners, and risk profiled development strategies. There would seem to be two consistent issues. The first is the lack of a common conceptual understanding of infrastructure and how it works in the broader socioeconomic environment. The second is an apparent lack of evidence or use of a common reference to inform planning and discussions. 
The lack of a common conceptual understanding affects everything from the approach to planning, assessment of benefit and commonality of purpose, and our understanding of through-life value and how to finance it. None of the particular tools that we use is wrong, per se, but they may not be the most appropriate to the situation. By any definition, infrastructure is a system that draws together structures, protocols for use and environmental dynamics to enable a capability or function. This system affects other systems and is supported by and influenced by yet other systems. The whole is thoroughly interconnected. We cannot fully understand one system in isolation, much less a multiplicity of individual or component systems.

Similarly, when something exists to enable an activity or capability, its value is defined by the degree of activity it enables. We can spend millions on a utility infrastructure system, but it has no value if no one uses it. Valuing infrastructure by the service it enables can present a challenge for infrastructure financing. Investment models that use real property cost or market value at the time of investment cannot capture the value of the infrastructure's use throughout its life.

Institutional investment in infrastructure as an asset class is still establishing itself. Many investment decision support models still use real property asset class valuation. Such models require assumptions, generalisations and estimates based on experience to inform the decision. These models are not designed for infrastructure investment decision-making. Therefore, the investor must use subjective assessment that is calibrated by experience, rather than an objective judgement based on available evidence. This evidence in context is the basis for the common reference. Institutional investors still wrestle with this, specifically how to inform the decision to invest. We often default to familiar models, defining the question by what we know we can answer. Consequently, we base our decision on a projection of value at the time of the investment. 
Through-life investment decision-making involves real change. Climate, technological and societal changes all directly influence socioeconomic behaviours and so the use of the infrastructure. These changes in use represent changes in value and risks. The material disclosures in the annual directors' reports for public corporations generally focus on corporate and compliance-type risks around these investments rather than the actual risks to continued operation and hence value change. In the absence of empirical data collected for the latter, the former relies more on estimate and subjective assessment. This issue extends beyond financial measures and speaks to the heart of corporate resilience. We can have the best corporate risk management and resilience package, but there is no business if we cease operating. The two are inseparable.

Similarly, infrastructure risk management and resilience are about both performance and contingent capability. We can align key risk indicators with our key performance indicators to present a real understanding of threats and opportunities to our infrastructure's value. The performance and capability of infrastructure will depend on how it is perceived and the broader community's sense of ownership. Infrastructure is one of the critical connectors between a corporation or municipality and the community. It is environmental, social and corporate governance in its very essence. Little wonder that it is or enables most of the 17 Sustainable Development Goals (SDGs).

The apparent lack of evidence used in planning and design is becoming a common refrain. Emphasised in the (UK) 2013 Armitt Review and in the 2016 National Infrastructure Commission report, Connected Future, the use of evidence allows us to establish a common reference. This common reference is a pure expression of fact, empirically based, associating an action with a series of consequences and an outcome. These connections are knowable and, in most regions, can be established using little more than satellite data and 
open-source references. Informed discussion informs perspective, collaborative problem identification and solving, and judgement-based decision-making.

In the absence of any (empirical) common reference, we necessarily rely on individual perceptions of the situation and deficiencies informed by our professional experience and bias. We are hardwired to infer an understanding of requirements from familiar fragments of patterns, which we then reinforce using curated corroborating evidence. This inevitably leads to optimism bias and failures in beneficial outcomes and cost management. If we can control the patterning of perceived deficiencies by better informing ourselves of what is, we can better define the actual problems. We must avoid defining the problem by the solution or tools we have to hand.

The willingness to study a situation and derive the problem requires a professional humility and patience that may be lacking, particularly when a time imperative drives the agenda. For example, following conflict or natural disaster, the reconstruction effort is frequently driven by an assumption of what pre-existed the catastrophe and how it worked, with a vision of what the solution should be based on what is familiar to the reconstruction engineers, planners and donors.

Often, there is an apparent mismatch between what was intended and the delivered benefit to the local community in postconflict reconstruction. The better use of evidence can fundamentally change practice and, I believe, reduce needless confrontation and expense.

When professional practitioners draw on a common concept of infrastructure and situational evidence, they can devise and deliver infrastructure systems that maintain value through life, benefiting all stakeholders. To me, this is the most explicit articulation of engineering in society. Engineering practice in infrastructure is inseparable from value, financing and the socioeconomic and natural environment that it functions within. Infrastructure 
is complex but needn't be complicated;

it is dynamic but inanimate.

With this book, I hope to inform a more cohesive, joined-up understanding of infrastructure from a first-principles perspective. Consequently, this is not jurisdictional or sector-specific. Though I am an engineer, writing predominantly for engineers, I do not feel that our language use always promotes understanding across all stakeholders. Why, for example, would we use different risk terminology from the finance and underwriting industries? That is not to say that technical definitions, codes and standards are necessarily wrong. We must understand these differences in interpretation and intelligently adjust if we are to speak with different audiences.

The emphasis of this book is understanding. I have endeavoured to keep it mercifully short, hoping that I may keep your interest through to the conclusion. I also hope to stimulate your further reading and exploration of the various topics covered. The concepts and practices are accessible. Where I have not been able to identify a commonly agreed theory or practice, I offer my perspective based on my research and experience. I annotate each instance where I do this, most notably around unifying purpose and beneficial capability. I use examples to illustrate points rather than whole case studies. I've avoided case studies because it is rare for the combination of conditions that led to the successful application of a particular practice in one location to replicate in another. Each situation (operation, location and context) is unique, even within the same city.

I begin by introducing infrastructure, exploring why it is essential and where the issues are and presenting my argument. I focus heavily on the theory of infrastructure. This theory leads to an exploration of value and the use of risk as both a tool and a language. I explore sustainability, resilience and protection in infrastructure systems before drawing all of these strands together to present infrastructure planning in theory. I balance 
this with a planning-in-practice perspective, exploring the noise and disconnects that can change the planned infrastructure's path and outcome. I conclude by exploring what the future holds for the infrastructure world.

\section{Acknowledgements}

I wish to acknowledge Federico Sittaro, Adonis Yatchew, Sanjay Khanna, Yannick Beaudoin, Yvonne Steiner, John Neily, Heather MacLean and Bryan Karney, with whom I have enjoyed many conversations about infrastructure's role and influence in society. I thank Michael Fenton, who encouraged and guided my development of this book. I particularly thank Carla, without whose support I would not have been able to write it. This book is for Joseph, Sophie and Alastair. 


\section{About the author}

Alexander H Hay PhD CEng PEng FICE RSES is a civil engineer specialising in infrastructure systems risk. He is a graduate of the University of Edinburgh and the University of Toronto, where he is an adjunct professor. He has 35 years of international experience in infrastructure development and fortifications in regions as diverse as the High Arctic, Europe, North Africa, the Middle East and Central Asia. Commissioned into the (British) Royal Engineers in 1989, he released in 2013 to pursue a career in industry. $\mathrm{He}$ is the founding principal of Southern Harbour Ltd, an independent infrastructure risk advisory service operating globally, advising on the through-life risk profiles of sustainable economic development strategies, and infrastructure reconfiguration and development. His research interest at the University of Toronto's Centre for Resilience of Critical Infrastructure is postconflict and postdisaster community rehabilitation and the role of infrastructure in regional socioeconomic transition to a low carbon dioxide emissions world. He joined the ICE knowledge panel on capacity building from 2007 to 2009 and has remained keenly interested in professional formation and development since, particularly in how to develop the competencies that the next generation of professional engineers will need to deal with the world they inherit. 
Downloaded by [] on [26/04/23]. Copyright @ ICE Publishing, all rights reserved. 


\section{About the collaborators}

Yannick C Beaudoin MA PhD is a senior economist and Director General for Ontario and Northern Canada with the David Suzuki Foundation. Previously, he was Chief Scientist with UNEP/ GRID-Arendal in Norway. He brings an 'economics for transition' lens to the Foundation, aimed at helping to enable a socially thriving and ecologically sustainable Canada. He applies art of change and participatory social processes to a variety of themes that include: adaptation to uncertain climate futures; embedding of local, traditional and indigenous knowledge in policy-, decision- and choice-making; and promoting a transition to a sustainable relationship between society and Nature. From his decade with the United Nations to his return to Canada in 2018, he has been facilitating conversations around the world, highlighting various solution pathways towards a well-being centric, \#beyondGDP economic system.

Sanjay Khanna BEd MFA GCB.D is a strategic advisor and foresight expert. Previously the futurist at global law firm Baker McKenzie, today Sanjay works with organisations to illuminate risks and opportunities associated with the converging crises of geopolitical fragmentation, socioeconomic reordering, population health issues, technological acceleration, and environmental and climate change. Sanjay has been interviewed by the Financial Times, The Globe and Mail and the Canadian Broadcasting Corporation, among others.

John Neily A/Commr (Retd) CEC PCIP is a strategic advisor in security and criminal intelligence, and a Certified Executive Coach. $\mathrm{He}$ served in the Royal Canadian Mounted Police for 35 years and as operations and operational support executive for specialised criminal investigations and operational readiness in the last 8 years. During this period, he was instrumental in organising the Canadian criminal intelligence-critical infrastructure interface with public and private sector partners. As Director of National Security and Emergency Management at the Conference 
Board of Canada, his team informed the shift in approach from critical infrastructure protection to critical infrastructure resilience, and published several cross-border reports. He was a strategic advisor to the Defence Research and Development Canada's Centre for Security Science for 4 years to integrate the first responder community in science and technology programmes. He is a sought-after consultant, facilitator and coach, working with established and upcoming leaders in both public and private sectors. 


\section{List of abbreviations}

A

AOI

Artificial intelligence

AOO

Area of operations

BFCA

Builders for Climate Action

BLM

Black Lives Matter

BOMA

Building Owners and Managers

Association

BRE Building Research Establishment

CAF Corporacion Andina de Fomento

CAPEX Capital expenditure

CC Carrying capacity

CDBB Centre for Digital Built Britain

COP Common operating picture

$\mathrm{CP} \quad$ Calculation plan

CPNI Centre for the Protection of the National Infrastructure

CPTED Crime Prevention Through

Environmental Design

CRA Canadian Revenue Agency

CRCI Centre for Resilience of Critical

Infrastructure

CSR Corporate social responsibility

DCS Distributed control system

DHS Department of Homeland Security

ERM Enterprise-wide risk management

ERSA European Regional Science Association

ESDA Exploratory spatial data analysis

ESG Environment, social and governance

FMEA Failure modes effects analysis

FMECA Failure modes effects and criticality analysis

GDPR General Data Protection Regulation

GPIF Government Pension Investment Fund

GRMI Global Risk Management Institute

GSD Ground sample distance

HTT Hazard travel time

IAO Indicators of anticipated outcome

ICE Institution of Civil Engineers

ICS Industrial control systems

ICT Information and communications technology

IDP Infrastructure development plan

IMF International Monetary Fund

ISO International Standards Organization 


$\begin{array}{ll}\text { LCA } & \text { Life-cycle analysis } \\ \text { LCI } & \text { Life-cycle inventory } \\ \text { LEED } & \begin{array}{l}\text { Leadership in Energy and } \\ \text { Environmental Design }\end{array} \\ \text { LoP } & \text { Level of protection } \\ \text { LRA } & \text { Location risk assessment } \\ \text { MAR } & \text { Maximum acceptable risk } \\ \text { MDG } & \text { Millennium Development Goals } \\ \text { MOC } & \text { Minimum operating capability } \\ \text { MRTC } & \text { Maximum realisable threat capability } \\ \text { MSC } & \text { Minimum sustainable capability } \\ \text { NOAA } & \text { National Oceanic and Atmospheric } \\ & \text { Administration } \\ \text { OECD } & \text { Organization for Economic Cooperation } \\ & \text { and Development } \\ \text { OPEX } & \text { Operation and maintenance expenses } \\ \text { OSPA } & \text { Oxford Scenario Planning Approach } \\ \text { PP } & \text { Planning point } \\ \text { PRI } & \text { Principles for Responsible Investment } \\ \text { PTSD } & \text { Post-traumatic stress disorder } \\ \text { RAMP } & \text { Risk Analysis and Management for } \\ & \text { Projects } \\ \text { RIBA } & \text { Royal Institute of British Architects } \\ \text { RICS } & \text { Royal Institution of Chartered Surveyors } \\ \text { RIMS } & \text { Risk and Insurance Management Society } \\ \text { ROI } & \text { Return on investment } \\ \text { SAID } & \text { Systems approach to infrastructure } \\ & \text { delivery } \\ \text { SARS } & \text { Severe acute respiratory syndrome } \\ \text { SCADA } & \text { Supervisory control and data acquisition } \\ \text { SDG } & \text { Sustainable Development Goals } \\ \text { SPV } & \text { Special purpose vehicle } \\ \text { TCFD } & \text { Task Force on Climate-related Financial } \\ & \text { Disclosures } \\ \text { TRA } & \text { Threat \& risk assessment } \\ \text { TUNA } & \text { Turbulence, uncertainty, novelty and } \\ & \text { ambiguity } \\ \text { UN } & \text { United Nations } \\ \text { UNDRR } & \text { UN Office for Disaster Risk Reduction } \\ \text { UNEP } & \text { UN Environment Programme } \\ \text { UNISDR } & \text { UN International Strategy for Disaster } \\ & \text { Reduction } \\ \text { UPS } & \text { Uninterruptable power supply } \\ \text { VaR } & \text { Value at risk } \\ & \end{array}$


VBIED Vehicle-borne improvised explosive device

VSOS Vitae system of systems

WCED World Commission on Environment and Development

WCR Whole cost of risk

WEF World Economic Forum

WHO World Health Organization

WRI World Resources Institute 